\title{
Catalytic ozonation of phenolic acids over a Mn-Ce-O catalyst
}

\author{
Rui C. Martins, Rosa M. Quinta-Ferreira* \\ GERSE, Group on Environment, Reaction and Separation Engineering, Department of Chemical Engineering, Faculty of Sciences and Technology, University of Coimbra, \\ Pólo II - Rua Sílvio Lima, 3030-790 Coimbra, Portugal
}

\section{A R T I C L E I N F O}

Article history:

Received 4 November 2008

Received in revised form 12 March 2009

Accepted 16 March 2009

Available online 25 March 2009

\section{Keywords:}

Catalytic ozonation

Catalyst characterization

Environment protection

Phenolic acids

Wastewater treatment

\begin{abstract}
A B S T R A C T
Catalytic ozonation of a simulated phenolic wastewater composed by six acids: syringic, vanillic, 3,4,5trimethoxybenzoic, veratric, protocatechuic and 4-hydroxybenzoic normally present in olive mill wastewaters was studied over a Mn-Ce-O laboratorial catalyst under different operating conditions. A high improvement in total organic carbon (TOC) degradation was observed even when low catalyst concentrations were used when compared with single ozonation. The influence of the medium $\mathrm{pH}$ in the performance of both single and catalytic ozonation was assessed in a wide range of pH values. An inhibitory effect in TOC removal was observed in the catalytic process performance at high pH values. The use of radical scavengers proved that this catalytic system does not follow a free radical pathway. No differences were observed between fresh and used catalyst structure and morphology by SEM and XRD. Nevertheless, a decrease on BET surface area was detected. Leaching of Mn as well as carbon adsorption due to organic intermediates deposition at the catalyst surface was analyzed for the recovered catalyst at the end of the experiments. The role of the catalyst in the catalytic ozonation pathway was discussed being concluded that the main mechanism should be developed through surface reactions involving both pollutants and ozone adsorption. A series of feed-batch trials was performed to test $\mathrm{Mn}-\mathrm{Ce}-\mathrm{O}$ activity along the time. A slight decrease on TOC removal was observed from the first to the second use, remaining the catalyst performance constant after the third run.
\end{abstract}

(c) 2009 Elsevier B.V. All rights reserved.

\section{Introduction}

One of the main problems mankind is facing nowadays is the reduction of the quantity and mostly the quality of the hydric resources. The growing industrial activity produces a high amount of effluents which when disposed without treatment in the natural resources may cause disastrous problems. It is, therefore, of prime importance to achieve effective treatment processes for these effluents.

The presence of phenolic mixtures in wastewaters is a common factor shared by a number of industries mainly the agro-industries [1]. These organic compounds incorporate in the effluents a significant contaminant load due to their high toxicity, refractory character and high stability in aqueous medium [2]. In particular, the olive mill wastewaters (OMW) are of main importance in the Mediterranean area countries since about three quarters of the global olive oil production comes from this region [3]. The increasing volume of wastewaters produced in these industries characterized by a high chemical oxygen demand (COD), which can be in the range between 25 and $300 \mathrm{~g} \mathrm{O}_{2} \mathrm{~L}^{-1}$ in the worst cases, constitutes a major environmental problem to be solved.

\footnotetext{
* Corresponding author. Tel.: +351 239798723; fax: +351 239798703

E-mail address: rosaqf@eq.uc.pt (R.M. Quinta-Ferreira).
}

The classical management of these effluents such as the application of biological treatments involves many problems concerning their high toxicity and the low biodegradability. Therefore, other strategies must be carried out in order to remove the organic compounds and/or to reduce the bacteria inhibition of the OMW.

The oxidation by ozone has shown to be efficient for the abatement of phenolic compounds [2,4]. However, since total mineralization is often not reached the enhancement of ozonation efficiency is an important task and the combination of ozone with an adequate catalyst has already shown satisfactory results. In particular, the transition metal manganese (Mn) as been reported as active for catalytic ozonation [3-13]. Moreover, the use of $\mathrm{CeO}_{2}$ as support to $\mathrm{Ru}$ based catalysts led to good results in catalytic ozonation of succinic acid ozonation [14].

In the context of phenolic wastewaters, Carbajo et al. [1] studied the efficiency of a perovskite type catalyst for the abatement of a mixture of phenolic compounds as well as of industrial phenolic effluents: wine distillery, debittering stage to produce table olives and OMW.

The laboratorial composite catalyst $\mathrm{Mn}-\mathrm{Ce}-\mathrm{O}$ with a molar ratio of $\mathrm{Mn}$ and $\mathrm{Ce}$ of 70/30 has been studied in our research group and has shown to be an active and stable catalyst in the catalytic wet oxidation of a phenolic acids mixture [15] and several other species appertaining to different chemical groups namely: 
aldehydes, carboxylic acids and alcohols [16-18]. Moreover a synergetic effect between $\mathrm{Mn}$ and Ce was observed when $\mathrm{Mn}-\mathrm{Ce}-$ O (70/30) catalyst efficiency was compared with the respective metal oxides in the enhancement of catalytic ozonation of a phenolic acids mixture [19]. From a previous screening of catalysts for a phenolic mixture catalytic ozonation, involving laboratorial ceria based catalyst, commercial catalysts for environmental applications [20], $\mathrm{Mn}-\mathrm{Ce}-\mathrm{O}$ with a molar ratio between $\mathrm{Mn} / \mathrm{Ce}$ of 70/30 was identified as the most active catalyst in terms of mineralization achieved. Also, Faria et al. [21] identified the composite $\mathrm{Mn}-\mathrm{Ce}-\mathrm{O}$ as a promising catalyst on the mineralization of some selected organic pollutants rather than the correspondent single oxides. Therefore, the aim of this work addresses the study of the activity and stability of the $\mathrm{Mn}-\mathrm{Ce}-\mathrm{O}$ (70/30) catalyst in the catalytic ozonation of a simulated phenolic wastewater, composed of six selected acids, major pollutants in OMW, under different operational conditions.

\section{Experimental}

\subsection{Catalyst preparation and characterization}

Mn-Ce-O catalyst with a molar ratio between Mn/Ce of 70/30 was prepared by co-precipitation by the procedure described elsewhere [16]. The fresh and used catalysts were characterized at different scales/magnifications by scanning electron microscopy (SEM) with a JEOL JSM-5310 and by X-ray powder diffraction (XRD) analysis using Philips PW 3040/00 X'Pert analyzer. The determination of the $\mathrm{pH}$ of zero point charge $\left(\mathrm{pH}_{\mathrm{zpc}}\right)$ of $\mathrm{Mn}-\mathrm{Ce}-\mathrm{O}(70 / 30)$ was carried out following the procedure proposed by Rivera-Ultrilla et al. [22]. The catalysts content in $\mathrm{C}, \mathrm{H}, \mathrm{N}$ and $\mathrm{O}$ was determined by Elemental analysis with a Fisons Instruments EA 11081108 CHNS-O. The catalyst Brunauer-Emmet-Teller surface area $\left(S_{\mathrm{BET}}\right)$ was determined using nitrogen $\left(-196{ }^{\circ} \mathrm{C}\right)$ with an accelerated surface area and porosimetry analyzer (ASAP 2000, Micromeritics). Porosity, pore size distribution were determined by mercury porosimetry (Poresizer 9320, Micromeritics).

\subsection{Oxidation procedure}

Six phenolic acids typically found in OMW [23] were selected to prepare the synthetic effluent with a concentration of $100 \mathrm{mg} / \mathrm{L}$ of each: syringic acid (4-hydroxy-3,5-dimethoxybenzoic), vanillic acid (4-hydroxy-3-methoxybenzoic), 3,4,5-trimethoxybenzoic acid, veratric acid (3,4-dimethoxybenzoic), protocatechuic acid (3,4-dihydroxybenzoic) and 4-hydroxybenzoic acid (SigmaAldrich).

Ozonation and catalytic ozonation were carried out in a semibatch mode in a glass reactor described elsewhere [19]. The reactor was filled with $500 \mathrm{~mL}$ of the model solution. Ozone was produced from a pure oxygen stream (99.999\% Praxair, Portugal) in an ozone generator (MICROLAB 1579, $\mathrm{SPO}_{3}$, Portugal) and continuously bubbled in the liquid bulk by means of two gas diffusers with a flow rate $500-1500 \mathrm{~cm}^{3} / \mathrm{min}$ (measured at room conditions of pressure and temperature). A gas absorption bottle containing $10 \%(\mathrm{w} / \mathrm{v}) \mathrm{KI}$ (Panreac) solution was used to destroy the remaining ozone leaving the reactor. The ozone gas concentration was determined by an ozone analyzer BMT 963 vent (BMT, Berlin) being used a constant concentration of $20 \mathrm{~g} \mathrm{O}_{3} / \mathrm{Nm}^{3}$. In the catalytic experiments, the desired amount of catalyst was introduced into the reactor just before ozone being fed. To test the influence of the presence of radical scavengers sodium carbonate at $0.1 \mathrm{M}$ (Riedelde-Häen) or tert-butanol (Fluka) at $0.05 \mathrm{M}$ were used. Samples were periodically withdrawn and immediately filtered with $0.45 \mu \mathrm{m}$ disposable filters (Whatman) for further analysis. The same procedure was adopted when the adsorption capacity of the catalyst was evaluated but without the introduction of ozone into the system.

\subsection{Analytical techniques}

Total organic carbon (TOC) was determined with a Shimadzu 5000 Analyser, which operates based on the combustion/nondispersive infrared gas analysis method. Total Phenolic Content (TPh) was measured colourimetrically using a Folin-Ciocalteau reactant (Fluka). The procedure used is described elsewhere by Martins et al. [19]. The absorbance was determined in a spectrophotometer (T60 U, PG instruments). COD was determined according to the Standard Method 5220D [24]. Each sample was analyzed in triplicate. $\mathrm{pH}$ was monitored with a HANNA instrument-HI8711E. Parent compounds concentration was followed in a Knauer HPLC system. The oven from Jones Chromatography (model 7971 ) was set at $75{ }^{\circ} \mathrm{C}$ and a Eurokat $H$ column was used. $0.01 \mathrm{~N}$ $\mathrm{H}_{2} \mathrm{SO}_{4}$ at a flow rate of $1 \mathrm{~mL} / \mathrm{min}$ was the mobile phase in isocratic mode. $20 \mu \mathrm{L}$ volume of sample was injected via an autosampler (Knauer, Smartline 3800) and the detection was typically at $210 \mathrm{~nm}$. Both standards and the samples were periodically run in duplicate to test the reproducibility of the measurements. Atomic absorption was used to measure the leaching of manganese to the liquid phase and the analysis was performed in a spectrometer Perkin-Elmer 3300. In the experiments of ozone decomposition, ozone in the liquid phase was determined by the indigo colorimetric method according to the Standard Methods (1985) [24]. When catalyst was used, the measurement was made before solid filtration. In this case, a blank solution using a sample in which ozone was selectively destroyed by addition of glycine was prepared since manganese interferes in ozone determination.

\section{Results and discussion}

\subsection{Preliminary results}

Previous to the assessment of the main variables influence over the efficiency of catalytic ozonation of the phenolic acids mixture enhanced by $\mathrm{Mn}-\mathrm{Ce}-\mathrm{O}$ (70/30) some experiments were carried out in order to establish the experimental conditions where mass transfer resistances were negligible to ensure chemical regime. In this context, classical tests with different values of agitation speed $(N)$, particle size $\left(d_{p}\right)$ and gas flow rate were performed until the performance of the catalyst remained constant. Within the results obtained, the following experimental conditions were selected: $750 \mathrm{rpm}$ for stirring speed, $125-250 \mu \mathrm{m}$ for catalyst particles diameter and a gas flow rate feeding the reactor $500 \mathrm{~cm}^{3} / \mathrm{min}$.

The optimization of the catalyst load is an important task since the increase in the catalyst concentration above a certain value, when there is an excess of active sites available for reaction, does not involve an increase in the oxidation efficiency. Experiments were conducted at different catalyst loads and was verified an increase on catalyst load from 7 to $10 \mathrm{~g} / \mathrm{L}$ no improvement was obtained in mineralization percentage. The following experiments were performed using $10 \mathrm{~g} / \mathrm{L}$ of $\mathrm{Mn}-\mathrm{Ce}-\mathrm{O}$ (70/30).

\subsection{Wastewater depuration by ozonation and catalytic ozonation}

Fig. 1 compares total phenolic content (TPh) and total organic carbon (TOC) degradation for single ozonation and catalytic ozonation using $10 \mathrm{~g} / \mathrm{L}$ of catalyst load. As observed, ozonation of the phenolic mixture in the absence of catalyst is a feasible technology to eliminate the phenolic content of the effluent, once $\mathrm{TPh}$ suffers a quick degradation achieving up to $88 \%$ after $120 \mathrm{~min}$ of reaction. However, only a slight mineralization degree is reached with less than $24 \%$ of final TOC removed. As referred before, ozone 


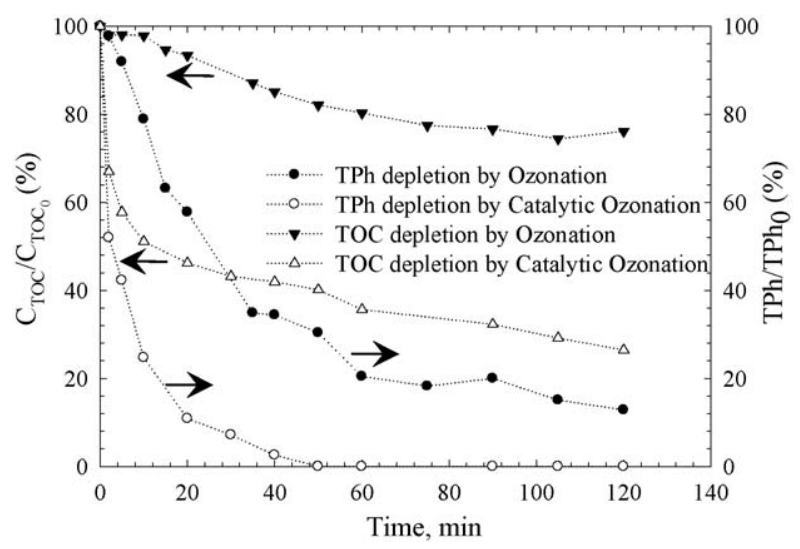

Fig. 1. Normalized TPh and TOC evolution during single and catalytic ozonation over Mn-Ce-O (70/30).

is very efficient in phenolic compounds removal, due to the strong electrophilic nature of ozone molecule that reacts directly with nucleophilic positions of aromatic rings [25]. This reactivity is enhanced when the ring is activated by the presence of electrondonating groups which is the case of hydroxyl $(\mathrm{OH})$, a strong activating group, and methoxy $\left(\mathrm{CH}_{3} \mathrm{O}\right)$ a moderate activating group, present in the phenolic acids under study. Nevertheless, the accumulation of different refractory intermediates, such as low molecular weight carboxylic acids, during ozonation process leads to a low level of mineralization [1]. TPh is totally removed after 50 min when catalytic ozonation over $\mathrm{Mn}-\mathrm{Ce}-\mathrm{O}$ (70/30) is performed, which truly enhances mineralization with a high TOC removal even at early reaction times. After $2 \mathrm{~min}, 33 \%$ of TOC was eliminated by catalytic ozonation, which corresponds to $9 \%$ more than single ozonation was able to reach after $120 \mathrm{~min}$, and a final degradation of $73.6 \%$ was observed for $120 \mathrm{~min}$ of reaction. Previously [20] the accumulation of carboxylic acids was verified (such as oxalic, malonic, acetic and formic acid) during the single ozonation of the synthetic phenolic effluent, nevertheless, when the treatment was performed in the presence of $\mathrm{Mn}-\mathrm{Ce}-\mathrm{O}$ total decomposition of those small acids was verified pointing out the importance of the catalyst on the enhancement of ozone activity which leads to higher mineralization degrees.

From previous experiments carried out [19] for the catalytic ozonation of the same synthetic phenolic wastewater, a synergetic effect was observed between $\mathrm{Mn}$ and Ce since the composite catalyst $\mathrm{Mn}-\mathrm{Ce}-\mathrm{O}$ showed higher activity than the correspondent single oxides $\left(\mathrm{MnO}_{2}\right.$ and $\left.\mathrm{CeO}_{2}\right)$. The same behaviour was observed by Faria et al. [21] once higher mineralization levels were obtained when the catalytic ozonation of sulfanic acid and aniline was performed over the bimetalic catalyst. This activity enhancement was attributed to the better redox properties of the catalyst [26].

An important parameter concerning the environmental legislation is the COD and in our case a reduction of $23 \%$ and $60 \%$ was achieved for ozonation and catalytic ozonation (using $10 \mathrm{~g} / \mathrm{L}$ of catalyst), respectively. Consequently, a significant improvement of $37 \%$ in COD degradation was also obtained by the combination of ozone with $\mathrm{Mn}-\mathrm{Ce}-\mathrm{O}$ (70/30) catalyst.

\subsection{Parent phenolic compounds decomposition}

Concentration for each parent phenolic acid was followed by means of HPLC analysis and Fig. 2 represents the degradation profiles along the time for all the compounds: protocatechuic, 4hydroxybenzoic, vanillic, syringic, 3,4,5-trimetoxybenzoic and veratric acids for both single ozonation (a) and catalytic ozonation over $\mathrm{Mn}-\mathrm{Ce}-\mathrm{O}$ (70/30) (b). The results obtained for the case
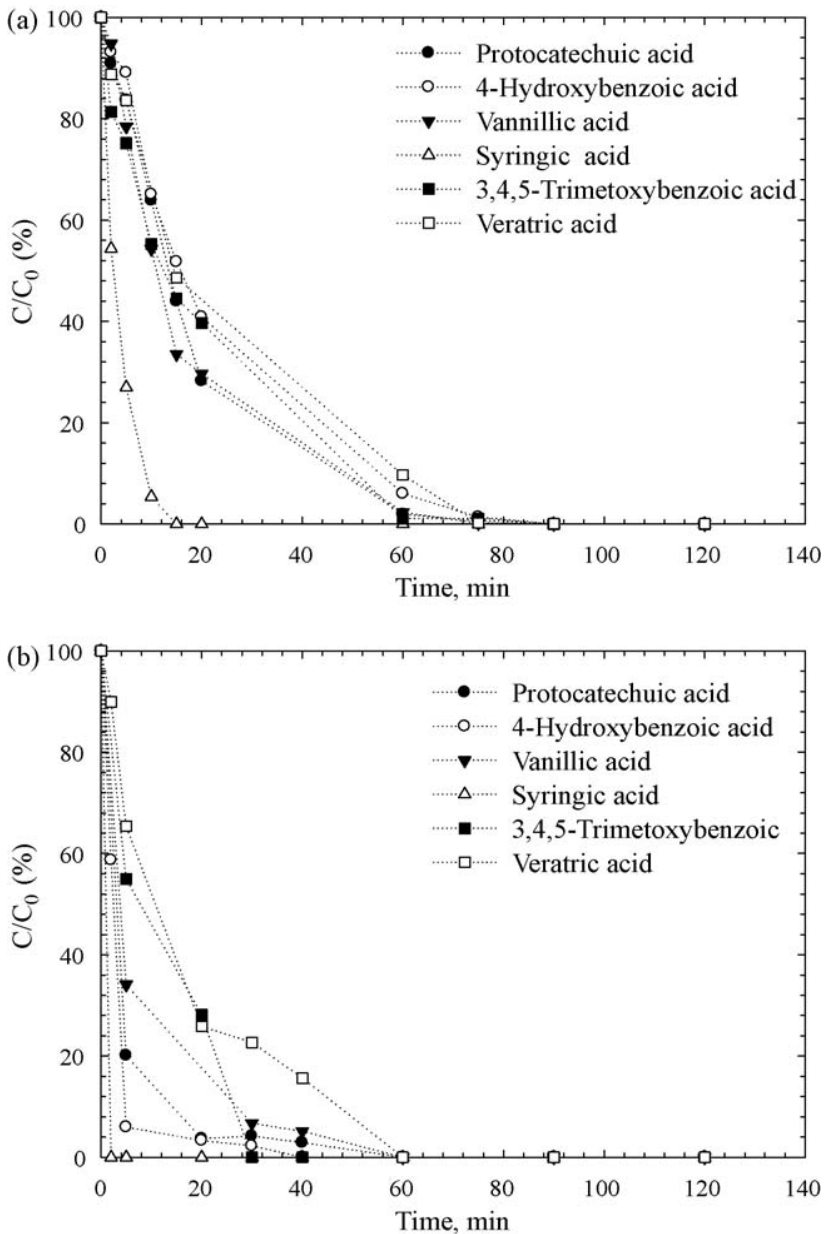

Fig. 2. Degradation profile of protocatechuic acid, 4-hydroxybenzoic acid, vanillic acid, syringic acid, 3,4,5-trimethoxybenzoic acid and veratric acid by (a) single and (b) catalytic ozonation.

involving the single ozonation of the mixture of the six acids prove the high ozone efficiency in the degradation of activated ring aromatic compounds since all the parent phenolic compounds are totally removed after $90 \mathrm{~min}$ of ozonation. It is interesting to recall $\mathrm{TPh}$ removal during single ozonation (Fig. 1) and compare the results with these parent phenolic compounds degradation profiles. In fact, TPh total removal is not achieved in the $120 \mathrm{~min}$ of reaction, while all the parent phenolic acids are destroyed along the treatment. Therefore it is possible to conclude that intermediates with phenolic character were formed during the ozonation process. Syringic acid showed the highest reactivity since total degradation was achieved for about 15 min of ozonation while 90 min were needed concerning the rest of the phenolic acids, which showed almost the same degradation profiles especially for the first 20 min of reaction. After this experimental time the following order of degradation rate was achieved for noncatalytic ozonation: syringic acid $\left(1 \mathrm{OH}, 2 \mathrm{CH}_{3} \mathrm{O}\right) \gg$ protocatechuic acid $(2 \mathrm{OH})>$ vanillic acid $\left(1 \mathrm{OH}, 1 \mathrm{CH}_{3} \mathrm{O}\right)>3,4,5$-trimetoxybenzoic acid $\left(3 \mathrm{CH}_{3} \mathrm{O}\right)>4$-hydroxybenzoic acid $(1 \mathrm{OH})>$ veratric acid $\left(2 \mathrm{CH}_{3} \mathrm{O}\right)$. It seems then to exist a relation between the number and type of aromatic ring substitutes groups (between brackets) and the reactivity of the acids once molecular ozone attacks especially through electrophilic pathways, which is facilitated by the presence of electron donating groups in the aromatic ring structure. The presence of some functional groups in benzene structure enhances the ring reactivity. Groups such as methoxy $\left(\mathrm{CH}_{3} \mathrm{O}\right)$ and hydroxyl $(\mathrm{OH})$ have the ability to provide electrons to 
the ring, enhancing, therefore, its nucleophilic character. Therefore, syringic acid with three substitute groups being one of them a strong electron donating group $(\mathrm{OH})$ is highly reactive, followed by protocatechuic and vanillic acid with two groups. The reactivity of protocatechuic acid is slightly higher than vanillic acid due to the presence of two strong electron donating groups $(\mathrm{OH})$ in protocatechuic structure, while vanillic only possesses one $\mathrm{OH}$ and a moderate electron donating group $\left(\mathrm{CH}_{3} \mathrm{O}\right)$. 3,4,5-Trimetoxybenzoic acid has a lower reactivity than the former acids in spite of owning three substituents groups; nevertheless all of them are moderate electron donating $\left(\mathrm{CH}_{3} \mathrm{O}\right)$. The same occurs with veratric acid, since even with two substitutes groups none of them is a strong electron donating one; therefore 4-hydroxybenzoic acid with only one $\mathrm{OH}$ group is slightly more reactive.

The presence of the catalyst leads to higher degradation rates for all the acids in study, reaching total removal after $40 \mathrm{~min}$ (Fig. 2b). Once more, syringic acid showed to be extremely reactive since total degradation of this compound occurred after 2 min of reaction. The following order of reactivity can be established: syringic acid $\gg 4$-hydroxybenzoic acid $\approx$ protocatechuic acid $\approx$ vanillic acid $>3,4,5$-trimetoxybenzoic acid $>$ veratric acid. The main change in the reactivity order concerning catalytic ozonation when compared with single ozonation is 4-hydroxybenzoic acid which in the catalytic system is the second more reactive acid while in ozonation was one of the less reactive.

\subsection{Effect of $p H$}

$\mathrm{pH}$ is a parameter of prime importance in aqueous ozone chemistry. This rises from the fact that $\mathrm{pH}$ influences both kinetics and pathways of ozone reactions. In fact, the double action of ozone in organic matter, which can be a direct or a free radical pathway, is highly affected by the solution $\mathrm{pH}$. At low $\mathrm{pH}$ the ozone molecule reacts exclusively with compounds with specific functional groups through selective reactions such as electrophilic, nucleophilic and dipolar addition (i.e. direct pathway) [27]. On the other hand, at alkaline conditions, ozone decomposes yielding hydroxyl radicals, which are highly oxidizing species that react in a non-selectively way with a wide range of organic and inorganic compounds in water (i.e. indirect ozonation) [28]. In heterogeneous catalytic systems, pH can affect the surface properties of metal oxides, which are covered by surface hydroxyl groups in the presence of water. Under different $\mathrm{pH}$ conditions, proton transference may occur on the surface of metal oxides [11], affecting, therefore, an eventual adsorption step of the reaction pathways. With the aim of optimizing the operational conditions and to compare both catalytic and non-catalytic ozonation at different $\mathrm{pH}$ values, the effect of this parameter in oxidation of the phenolic acids mixture was tested in a range between 3.4 and 9.5. For experiments involving $\mathrm{pH} 5,7$ and $9.5, \mathrm{NaOH}(0.1 \mathrm{M})$ was used to maintain the $\mathrm{pH}$ at the desired value.

Fig. 3a shows the time profiles for TPh removal for the mixture of phenolic acids at different pH values: 3.4 (phenolic mixture natural $\mathrm{pH}), 5,7$ and 9.5 in what concerns single ozonation. In all $\mathrm{pH}$ range, a fast phenolic content decay was observed, even if total phenolic content degradation was not achieved in any experiment. However, increasing $\mathrm{pH}$ from 3.4 to 9.5 leads to a removal enhancement from $84 \%$ to $95 \%$, respectively after $120 \mathrm{~min}$ of ozonation. At $\mathrm{pH}$ values higher than the acid ionization constant, $\mathrm{p} K_{a}$ (which for phenolic acids is around 4.0-4.5) the acids are present in solution dissociated in anions which are more reactive than the undissociated forms [29]. For the experiment performed at $\mathrm{pH}=7$ a different behaviour was observed. In fact, lower TPh degradation percentages than for $\mathrm{pH}=5$ were detected for the first $90 \mathrm{~min}$ of reaction probably due to the formation of intermediates with phenolic character; nevertheless after this reaction time best
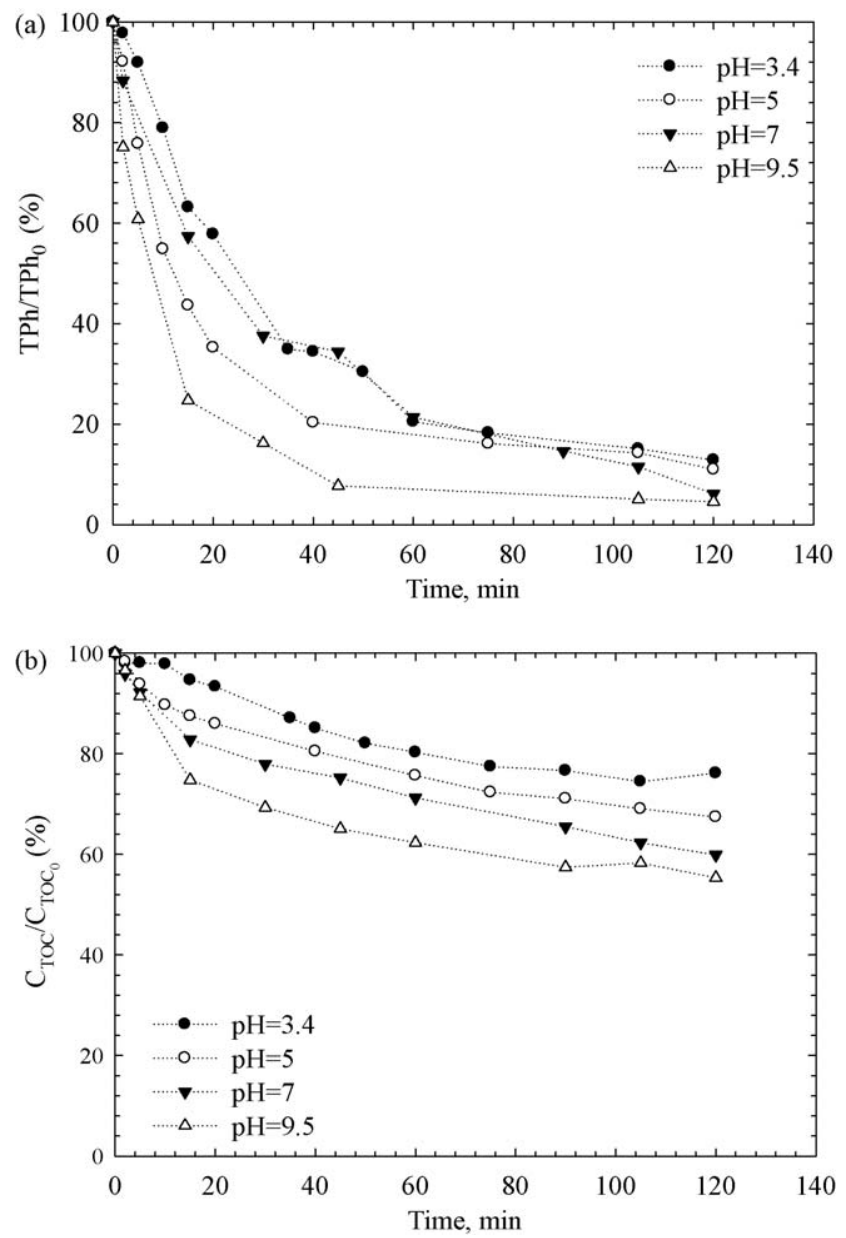

Fig. 3. Normalized (a) TPh and (b) TOC concentration (\%) as function of time for single ozonation at different solution $\mathrm{pH}$.

results were achieved for the higher $\mathrm{pH}$. At alkaline conditions, hydroxide ions are initiators of chain reactions involving the decomposition of ozone and leading to the formation of highly reactive hydroxyl radicals which increase the reaction rate [28]. As a consequence, the increase of $\mathrm{pH}$ solution leads to a more efficient TOC removal (Fig. 3b), from $23 \%$ at $\mathrm{pH}=3.4 \%$ to $44 \%$ at $\mathrm{pH}=9.5$ after 120 min of ozonation. Furthermore, at low $\mathrm{pH}(\mathrm{pH}=3.4)$ one can observe for single ozonation an induction period at the first 15 min of reaction, where TOC removal is negligible, which is not present at higher $\mathrm{pH}$ values. Enhancement with $\mathrm{pH}$ was also observed for COD removal: $23 \%(\mathrm{pH}=3.4)$ to $62 \%(\mathrm{pH}=9.5)$ after 120 min of reaction, meaning that, even if the TOC degradation is not so high ( $44 \%$ for $\mathrm{pH}=9.5$ ), the remaining organic compounds are in a higher oxidation state with lower COD values.

In what concerns catalytic TPh degradation (Fig. 4a), only a slightly variation is observed in the earlier times of reaction when different $\mathrm{pH}$ values are used being the results vaguely better with the rise of $\mathrm{pH}$. Nevertheless total removal of TPh was achieved after $40 \mathrm{~min}$ for all the $\mathrm{pH}$ range in use. From the experimental results for TOC catalytic removal (Fig. $4 \mathrm{~b}$ ) there is a considerable inhibitory effect at high solution $\mathrm{pH}$ being obtained a TOC removal after $120 \mathrm{~min}$ of $74 \%$ and $58 \%$ at $\mathrm{pH}=3.4$ and $\mathrm{pH}=9.5$, respectively. This indicates that the organic compounds are better catalytically degraded at low pH contrarily to single ozonation, which points out that the main degradation mechanism in ozonation over a MnCe-O (70/30) catalyst may not develop through the formation of aqueous hydroxyl radicals. Moreover, the differences of using several $\mathrm{pH}$ values are more relevant in TOC reduction than in TPh 

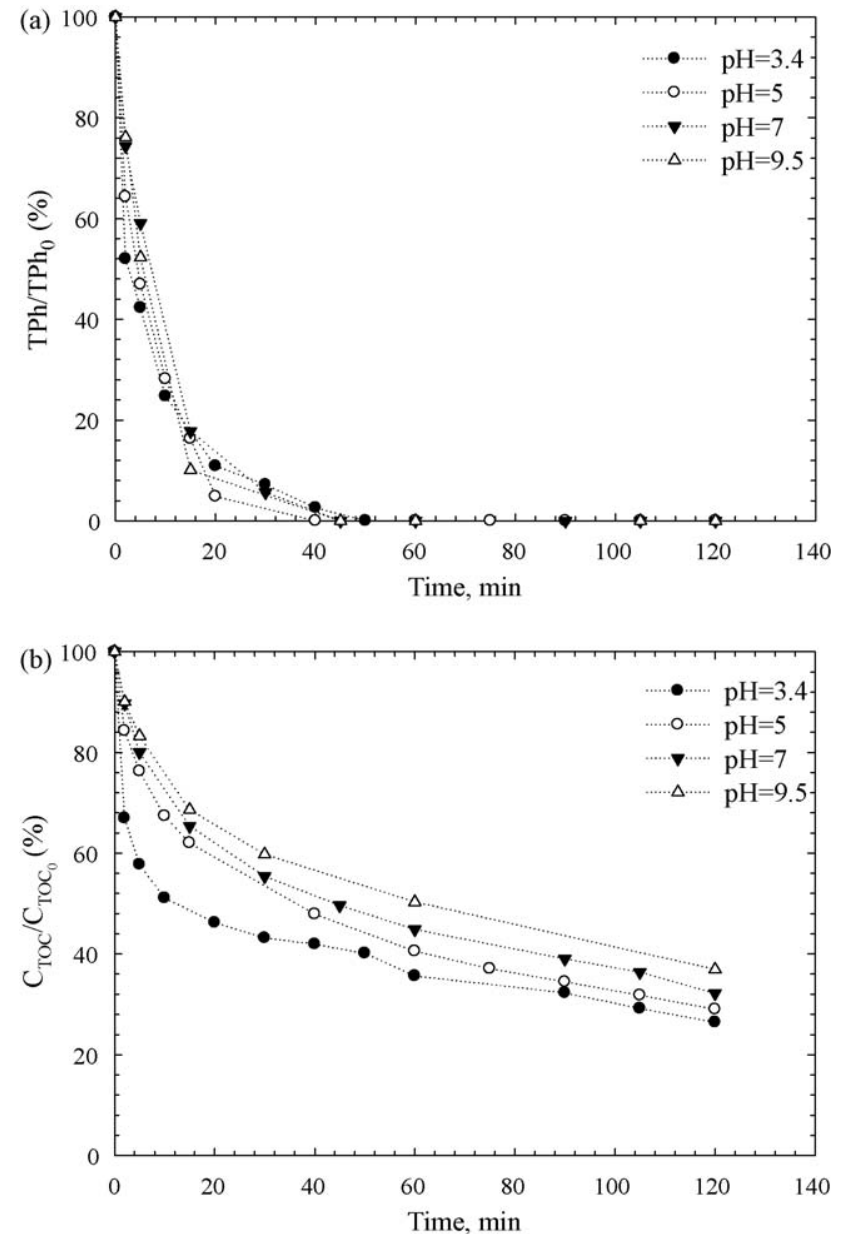

Fig. 4. Normalized (a) TPh and (b) TOC concentration (\%) as function of time for catalytic ozonation at different solution $\mathrm{pH}$.

removal which may be due to the fact that in this heterogeneous media the effect of $\mathrm{pH}$ in the surface proprieties of the catalyst is more important for the intermediates total mineralization than for the phenolic compounds degradation that are already highly reactive with ozone itself. Table 1 compares TOC removal after 120 min of ozonation and catalytic ozonation for the different medium $\mathrm{pH}$ values tested. As it can be observed, the catalyst action in TOC degradation is more evident for low pH values. In fact, a difference of $50 \%$ of mineralization is achieved between ozonation and catalytic ozonation for $\mathrm{pH}=3.4$ while for $\mathrm{pH}=9.5$ the difference decreases to $18 \%$. The solution $\mathrm{pH}$ has high influence in the surface properties of the catalyst particularly related with the $\mathrm{pH}_{\mathrm{zpc}}$, which for $\mathrm{Mn}-\mathrm{Ce}-\mathrm{O}(70 / 30)$ is 4.8 . Therefore at higher reaction medium $\mathrm{pH}$ the catalyst is negatively charged as well as the phenolic and carboxylic acids (with a $\mathrm{p} K_{a}$ around 4.0-4.5), creating repulsive electrostatic interactions between catalyst and pollutants that will inhibit the surface reactions [5].

An interesting question is the comparison between parent compounds and TOC and COD removal since these values give information about the selectivity of the reaction towards carbon dioxide and partially oxidised by-products, respectively. All the parent phenolic compounds were totally degraded in the experiments developed and, therefore, one can consider $X_{\text {parent }}$ compounds $=100 \%$ at the end of the oxidation experiments. The higher the difference between parent compounds decomposition and COD degradation, the higher is the quantity of partially oxidised compounds in solution. Meanwhile, the difference between the parent compounds degradation level and TOC removal gives the selectivity of the process towards the formation the end-products carbon dioxide and water, since as closer these two values, more selective is the process towards total mineralization. Table 1 resumes TOC removal and COD removal after 120 min of reaction for both non-catalytic and catalytic ozonation at the different $\mathrm{pH}$ values in use. For single ozonation both TOC and COD degradation are improved with the raise of the $\mathrm{pH}$ of operation. However TOC removal is always lower than COD removal meaning that the reaction develops towards partially oxidised organic products rather than through the formation of carbon dioxide and water. This was expectable since single ozonation is known to have high capacity to oxidize molecules with high electronic density leading to the formation of low weight carboxylic compounds which are in a higher oxidation state. Low mineralization levels are, nevertheless, obtained due to the refractory character of these species. In what concerns catalytic ozonation, until a neutral $\mathrm{pH}$ value, TOC removal is higher than COD removal and, therefore, the reaction selectively develops towards carbon dioxide and water, involving then higher mineralization levels of the effluent. However, at $\mathrm{pH}=9.5 \mathrm{COD}$ depletion is slightly higher than TOC abatment, meaning that the raise in $\mathrm{pH}$ up to alkaline values inhibits total mineralization relatively to partial oxidation.

\subsection{Influence of the presence of free radical scavengers}

Some studies concluded that the generation of aqueous hydroxyl radicals due to ozone decomposition at the solid surface is mainly responsible for the improvement of catalytic ozonation $[9,12]$. A different conclusion was, however, taken from the work of Ma et al. [11] when using $\mathrm{MnO}_{x} / \mathrm{GAC}$ catalyst to improve nitrobenzene ozonation since, in this case the presence of radical scavengers ( $t$-butanol) had no effect over the catalytic treatment efficiency. Therefore, in order to assess the possibility of the intervention of aqueous free radicals in the global pathway of catalytic ozonation over the $\mathrm{Mn}-\mathrm{Ce}-\mathrm{O}$ (70/30) catalyst, an inorganic and an organic radical scavenger were used, sodium carbonate and t-butanol. As it can be observed in Fig. 5a and b, which represent $\mathrm{TPh}$ and TOC reduction profiles along the experimental time for both catalytic ozonation and catalytic ozonation in the presence of $0.1 \mathrm{M}$ in carbonate or $0.05 \mathrm{M}$ in tbutanol $(\mathrm{pH}=3.4)$ respectively, no significant differences occur between the runs either in terms of TPh or TOC depletion. Maybe a slight inhibitory effect is observed for both parameters reduction in the presence of the organic scavenger which can be explained by the competition between the target compounds and t-butanol for the active sites of the catalyst reducing the global efficiency of the process. The main conclusion obtained from these results points

Table 1

TOC and COD removal after 120 min of single and catalytic ozonation at different $\mathrm{pH}$ values.

\begin{tabular}{|c|c|c|c|c|c|c|c|c|}
\hline & $\mathrm{pH}$ & & & & & & & \\
\hline & 3.4 & & 5 & & 7 & & 9.5 & \\
\hline$\%$ & $\mathrm{TOC} \mathrm{TOC}_{0}$ & $\mathrm{COD} / \mathrm{COD}_{0}$ & $\mathrm{TOC} \mathrm{TOC}_{0}$ & $\mathrm{COD} / \mathrm{COD}_{0}$ & $\mathrm{TOC} \mathrm{TOC}_{0}$ & $\mathrm{COD} / \mathrm{COD}_{0}$ & $\mathrm{TOC} \mathrm{TOC}_{0}$ & $\mathrm{COD} / \mathrm{COD}_{0}$ \\
\hline Single ozonation & 24 & 27 & 33 & 44 & 40 & 60 & 45 & 62 \\
\hline Catalytic ozonation & 74 & 59 & 71 & 54 & 69 & 59 & 63 & 67 \\
\hline
\end{tabular}



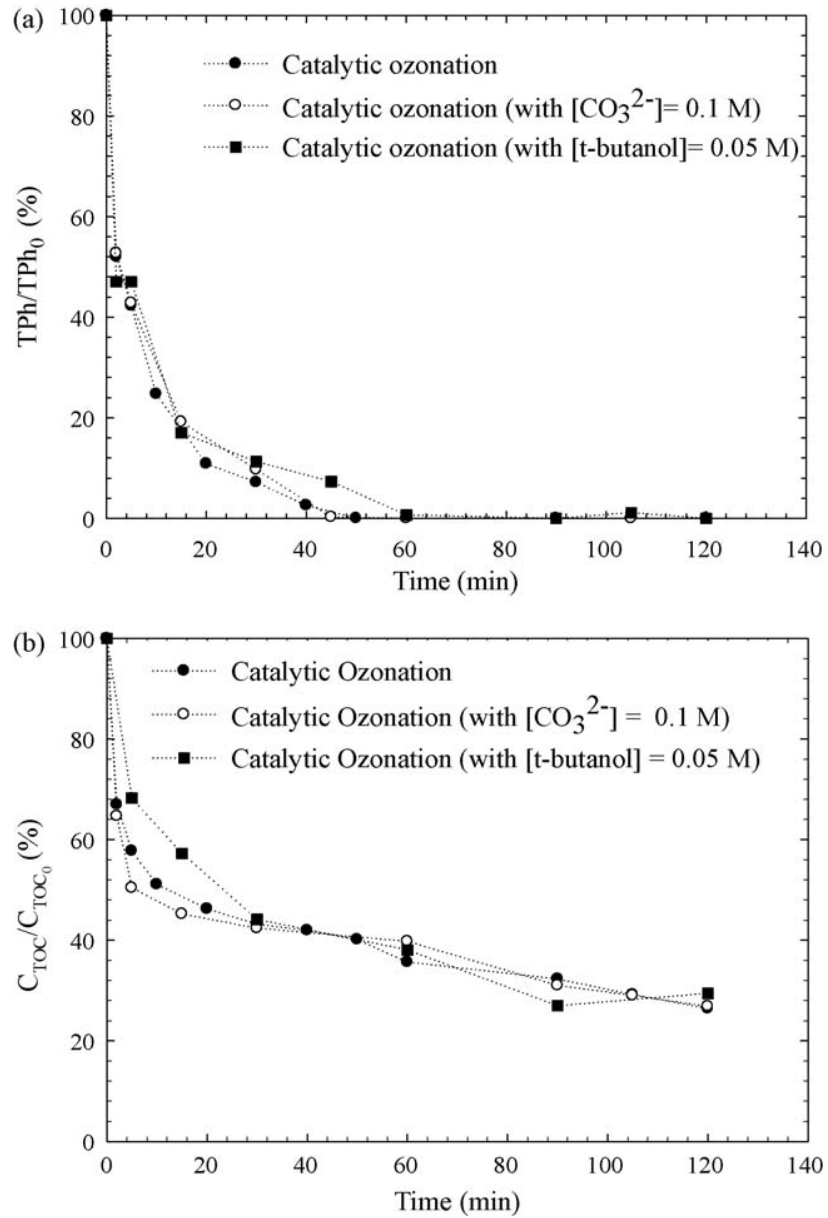

Fig. 5. Normalized (a) TPh and (b) TOC concentration for catalytic ozonation in the presence and absence of radical scavengers.

out the occurrence of solid reactions rather than the generation of free radicals [1].

\subsection{Fresh and used catalyst characterization}

The morphology of Mn-Ce-O (70/30) was observed at different magnifications of SEM for the fresh and used catalyst ( $\mathrm{pH}=3.4$ ). Fig. 6 compares both fresh (a) and used (b) catalysts and, as it can be observed, no significant differences were found in the catalyst after the catalytic ozonation for the different scales/magnifications examined $(1000 \times ; 3500 \times ; 15,000 \times)$. However, when Mn-Ce-O (70/30) was used in catalytic wet oxidation (CWO), different results were achieved since in this case filaments with different lengths were formed in the used catalyst surface. These whiskers were identified as $\mathrm{MnOOH}$ and/or $\mathrm{MnO}_{2}$ during the CWO of acrylic acid [17], ethylene glycol [18] and a mixture of phenolic acids usually present in OMW [15].

$\mathrm{X}$-ray diffraction analysis of the fresh and the used catalyst $(\mathrm{pH}=3.4)$ was performed and no significant differences were detected in terms of the catalyst structure before and after the catalytic ozonation of the phenolic mixture, unless slightly more intense peaks observed for the used catalyst. In both cases two main phases were detected cerianite $\left(\mathrm{CeO}_{2}\right)$ and pyrolusite $\left(\mathrm{MnO}_{2}\right)$.

The BET isotherm for $\mathrm{Mn}-\mathrm{Ce}-\mathrm{O}(70 / 30)$ before and after 120 min of catalytic ozonation $(\mathrm{pH}=3.4)$ was determined. Both isotherms show a hysteresis loop for high range of relative pressure which is related with the capillary condensation/ evaporation in mesoporous structures. After the catalyst use in the catalytic ozonation of the phenolic mixture the BrunauerEmmet-Teller surface area $\left(S_{\mathrm{BET}}\right)$ decreased from 109 to $83 \mathrm{~m}^{2} / \mathrm{g}$, corresponding to a decrease of $24 \%$. From the pore size distribution analysis, an average pore diameter decreased from 0.0179 to $0.0143 \mu \mathrm{m}$ (pore sizes corresponding to mesoporous/macroporous) was observed from the fresh to the spent catalyst. Both fresh and used materials present pores with diameters in the range of 0.006 and $0.1 \mu \mathrm{m}$ (in accordance with the previous statement of a mesoporous/macroporous structure). It should be noticed that the mercury porosimetry only allows to detect pores with diameters higher than $7 \mathrm{~nm}$ (for a maximum intrusion pressure of $30,000 \mathrm{psia}$ ), and, therefore, the average pore diameters are, probably, a little lower than the presented values.

Also in the catalytic ozonation process, Delanöe et al. [14] reported that a lost on the structure of the $\mathrm{Ru} / \mathrm{CeO}_{2}$ catalyst was observed. This fact was related with reactions which lead to the sintering of ruthenium that precipitated as clusters and reduced the specific surface area of the catalyst. We believe that in our case also some structure changes of the catalyst are likely to occur, which will be further investigated.

\subsection{Catalyst stability}

Catalyst deactivation is an important factor concerning heterogeneous catalysis. Metal leaching to the liquid phase besides representing an important deactivation factor, may also become a second pollution source. In the experiment with the best mineralization results, i.e., $10 \mathrm{~g} / \mathrm{L}$ of $\mathrm{Mn}-\mathrm{Ce}-\mathrm{O}$ (70/30) with a gas concentration of $20 \mathrm{~g} \mathrm{O}_{3} / \mathrm{m}^{3}$ and a $\mathrm{pH}$ value equal to 3.4 , $33.5 \times 10^{-3} \mathrm{~g} / \mathrm{L}$ of $\mathrm{Mn}$ was detected in the liquid phase after 120 min of reaction, which corresponds to $0.7 \%$ of the initial Mn concentration $(4.78 \mathrm{~g} / \mathrm{L})$. In heterogeneous catalysis, $\mathrm{pH}$ is a parameter of main importance due to the strong impact exerted in the stability of the catalyst, especially when transient metallic species are used [11]. The maximum Mn leaching $33.5 \times 10^{-3} \mathrm{~g} / \mathrm{L}$ of $\mathrm{Mn}$ was detected for the extreme acidic conditions used $(\mathrm{pH}=3.4)$, even if it is a low percentage $(0.7 \%)$ of the initial Mn loaded to the reactor. A high decrease of $62 \%$ is observed when $\mathrm{pH}$ rises from to $5.0\left(3.8 \times 10^{-3} \mathrm{~g} / \mathrm{L}\right.$ of $\left.\mathrm{Mn}\right)$ and at neutral conditions the $\mathrm{Mn}$ leached is also a small fraction of the initial $\mathrm{Mn}$ in the catalyst $(0.09 \%)$. However, the Mn concentration at the liquid bulk rises again to $12.3 \times 10^{-3} \mathrm{~g} / \mathrm{L}(0.26 \%$ of the initial $\mathrm{Mn})$ when extreme alkaline conditions $(\mathrm{pH}=9.5)$ are used. This behaviour is typical of amphoteric metals with higher solubility values for extreme acidic and alkaline values. In what concerns $\mathrm{Ce}$, cerium oxide is reported to be insoluble in water and, therefore, no important leaching quantities are usually found for this earth rare metal. Hamoudi et al. [30] verified that the dissolved Ce after the CWO over $\mathrm{Mn}-\mathrm{Ce}-\mathrm{O}$ of a phenolic mixture was always below the detection limit of the measurement technique (plasma emission spectroscopy) being the Mn leached much more important. Therefore, one admitted as appropriate to consider no leaching problems associated to cerium.

At the end of the experiments the carbon adsorption due to the deposition on the catalyst surface of organic intermediates was also evaluated since deactivation may occur due to the formation of carbonaceous deposits at the catalyst surface adsorbed on active sites. However in this study, low values of carbon were detected in the recovered catalyst after $120 \mathrm{~min}$ of reaction corresponding to $36.4 \mathrm{mg} / \mathrm{L}$ of carbon in the $10 \mathrm{~g} / \mathrm{L}$ of catalyst initially charged in the reactor and approximately $8.4 \% \mathrm{C}(\mathrm{w} / \mathrm{w})$ of the initial TOC (for the experiment at $\mathrm{pH}=3.4$ ). Therefore, TOC was effectively removed by oxidation (73.6\%) and not by simple adsorption into the catalyst.

A good catalyst should still be active along several hours of operation. Reusing the catalyst along sequential feed-batch trials 


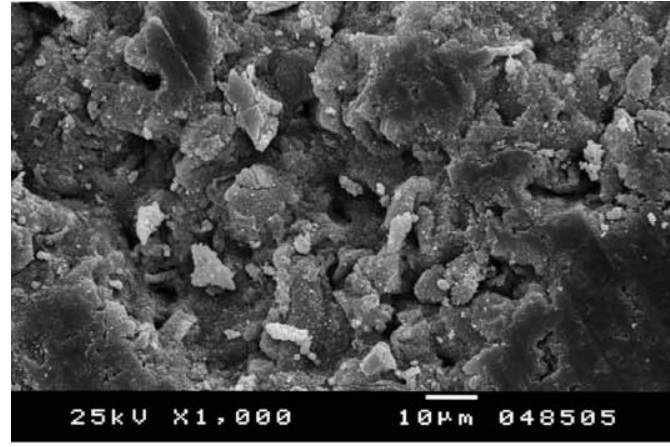

(a1)

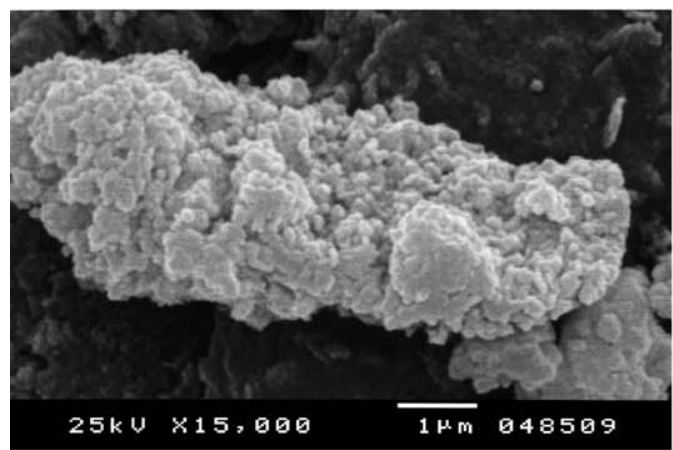

(a3)

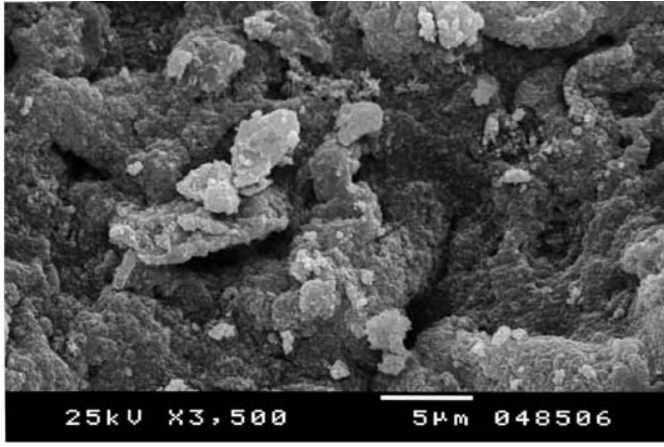

(a2)

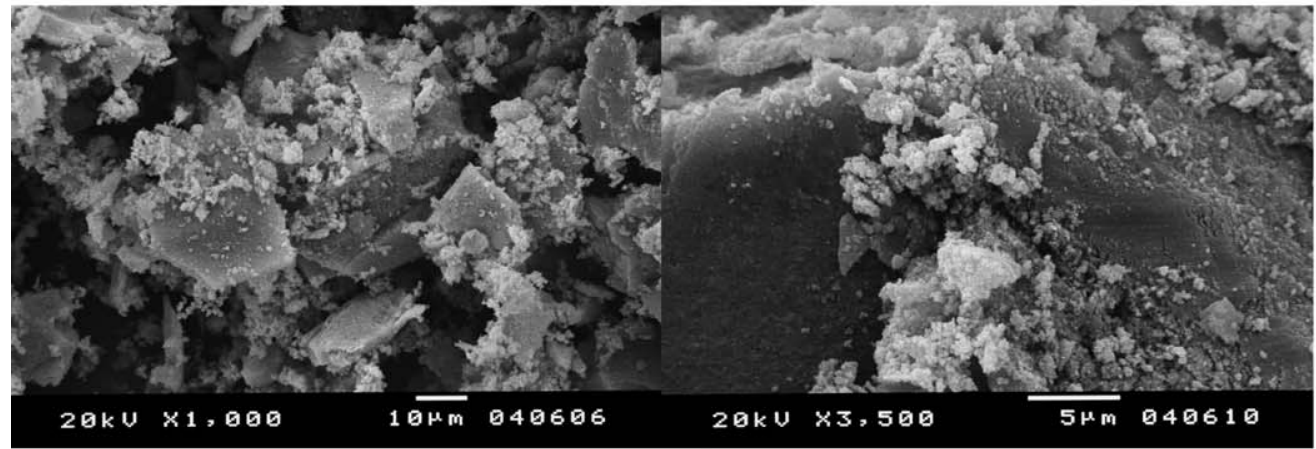

(b1)

(b2)

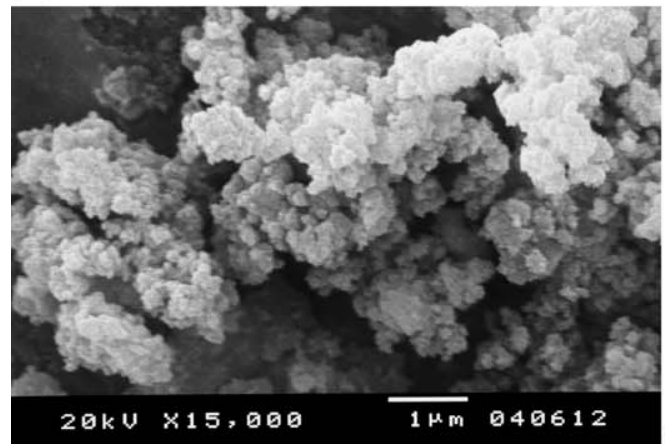

(b3)

Fig. 6. SEM photographs showing different scales/magnifications of (a) fresh and (b) used Mn-Ce-O (70/30).

can give a first idea about its performance. Therefore, systematic injections (each $120 \mathrm{~min}$ ) of a pre-calculated phenolic mixture solution were done in order to obtain a concentration close to the initial value ( $370 \mathrm{mg} \mathrm{C} / \mathrm{L}$ ). TOC was measured along the different runs and the results are shown in Fig. 7. Even though TPh degradation keeps unchanged, a slight decrease on TOC removal efficiency is found after the second run, probably related with the decrease of the BET area detected after the first use of the catalyst from 109 to $83 \mathrm{~m}^{2} / \mathrm{g}$. Nevertheless, the catalytic system always shows a high degradation rate in the first minutes of each run corresponding to almost $33 \%$ of mineralization after $2 \mathrm{~min}$ in all experiments. After the third run, the final TOC removal (for each injection) is always around $50 \%$, which is still a better performance in terms of mineralization than single ozonation which only reaches $24 \%$ TOC depletion. In order to evaluate the possible effect of homogeneous catalysis due to the Mn leached, a run using manganese ions (with a concentration correspondent to the maximum of $\mathrm{Mn}$ leached, $33.5 \times 10^{-3} \mathrm{~g} / \mathrm{L}$ ) was compared with 


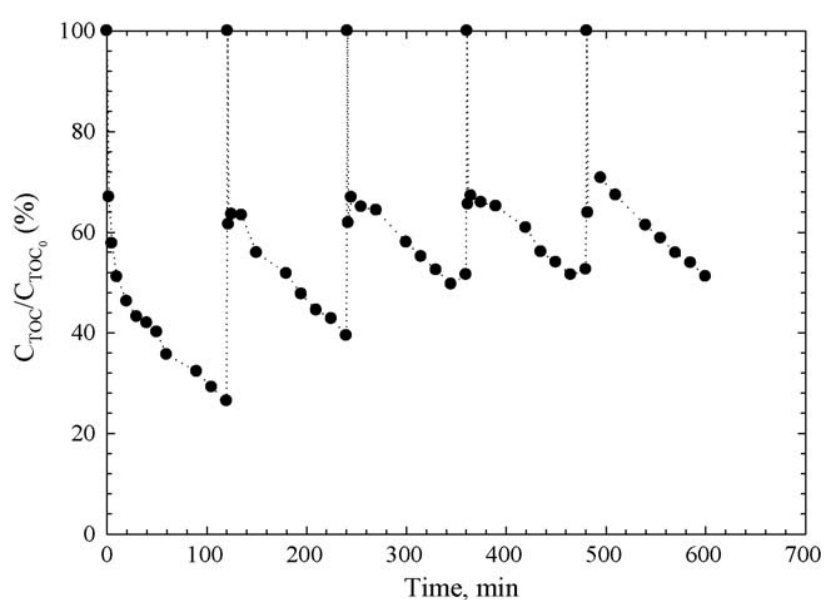

Fig. 7. Normalized TOC concentration (\%) as function of time for a sequential batch experiment with phenolic mixture injection each $120 \mathrm{~min}$.

single ozonation and no appreciable differences where noted, which proves the negligible role of the leached ions in the catalytic activity.

\subsection{Role of the catalyst over catalytic ozonation pathway}

In catalytic ozonation, three general pathways may be involved [31] adsorption of ozone over the catalyst with the formation of active species which will react with the pollutants in liquid phase; adsorption of the organic pollutant and reaction with free ozone (aqueous or gaseous) or adsorption of both reactants with further surface reaction. In this context, to assess the role of the catalyst over the global catalytic ozonation pathway the capacity of Mn$\mathrm{Ce}-\mathrm{O}(70 / 30)$ to either adsorb organic compounds or/and decompose ozone was investigated.

The catalyst adsorption capacity was evaluated at different medium pH values, namely, 3.4 (Fig. 8a), 5 (Fig. 8b), 7 (Fig. 8c), 9.5 (Fig. 8d) and compared with TOC removal along the time for single and catalytic ozonation. The adsorption capacity of the catalyst is extremely related with the medium $\mathrm{pH}$. In fact, while for $\mathrm{pH}=3.4$ high TOC adsorption occurred with almost $60 \%$ of TOC removed after $20 \mathrm{~min}$, the increase of $\mathrm{pH}$ reduced the catalyst ability for the organic compounds adsorption with only $34 \%$ of TOC removed from the liquid phase at $\mathrm{pH}=5$. The removal percentage was reduced to $27 \%$ and $25 \%$ for $\mathrm{pH}=7$ and $\mathrm{pH}=9.5$, respectively. These results may be explained by both $\mathrm{pH}_{\mathrm{zpc}}$ of the catalyst (4.8) and the $\mathrm{p} K_{a}$ of the phenolic acids (between 4.0 and 4.5). In fact, for medium $\mathrm{pH}$ values higher than 4.8 both catalyst surface and phenolic acids are negatively charged, leading therefore to repulsive electrostatic interactions developed between $\mathrm{Mn}-\mathrm{Ce}-$ $\mathrm{O}(70 / 30)$ and the phenolic acids anions, inhibiting as a consequence the adsorption process. The catalytic removal efficiency of TOC by ozone over Mn-Ce-O (70/30) is no doubt related with the catalyst ability to adsorb the organic compounds, since, as was already referred, an inhibition is also observed in catalytic ozonation with $\mathrm{pH}$ raise. Therefore, pollutants adsorption at the catalyst surface, with further oxidation (since a final low carbon content was detected in the previous section) seems to
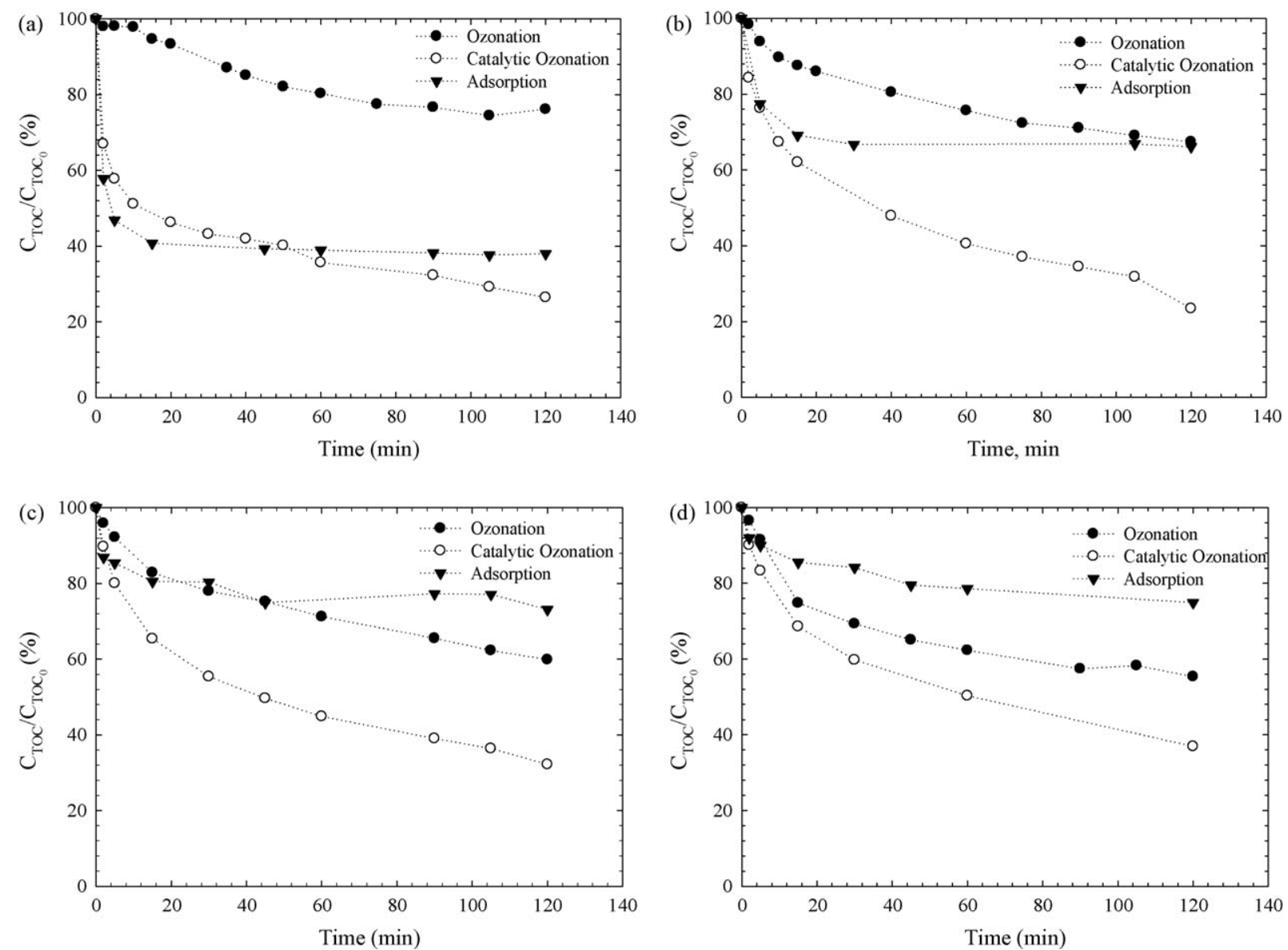

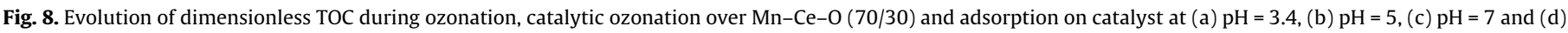
$\mathrm{pH}=9.5$. 


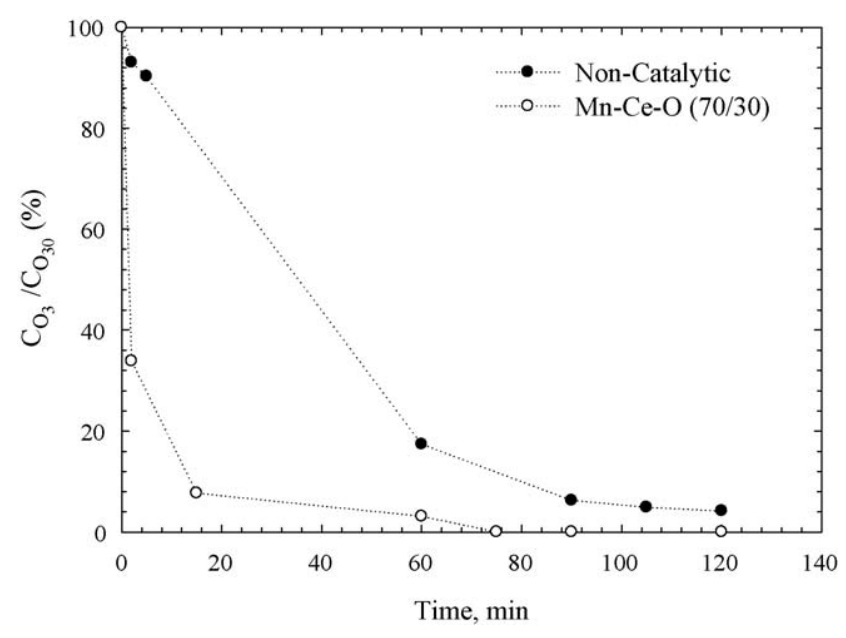

Fig. 9. Dimensionless aqueous ozone concentration during non-catalytic and over Mn-Ce-O (70/30) ozone decomposition ( $\mathrm{pH}=3.4)$.

be one of the reaction steps for the effluent mineralization in this catalytic system.

Another important stage in heterogeneous catalytic ozonation is the action of the catalyst over ozone. The first conclusion is that the presence of the catalyst improves the efficient use of ozone and reduces the waste since a lower concentration of this oxidant is lost in the off-gas when compared with the non-catalytic experiment. To test the catalyst ability to decompose/adsorb ozone, two runs involving ozone decomposition, non-catalytically and over Mn$\mathrm{Ce}-\mathrm{O}(70 / 30)$, were performed. In this context, distillate water was previously saturated with ozone $\left(1.5 \times 10^{-4} \mathrm{M}\right)$ being afterwards the gas feed turned off and samples periodically withdrawn to measure dissolved ozone. In the catalytic decomposition, $1.5 \mathrm{~g}$ of $\mathrm{Mn}-\mathrm{Ce}-\mathrm{O}$ (70/30) were immediately introduced in the reactor after the gas feed being removed. Since $\mathrm{pH}$ has high influence on ozone aqueous decomposition [32] the water $\mathrm{pH}$ was maintained at 3.4. Fig. 9 depicts dimensionless remaining ozone concentration along time for both non-catalytic and catalytic ozone decomposition. According to literature [33-35] $\mathrm{Mn}$ and Ce are known to be active for the decomposition of both aqueous and gaseous ozone. In fact, in our experiments, the presence of $\mathrm{Mn}-\mathrm{Ce}-\mathrm{O}(70 / 30)$ improved ozone decomposition with a high decrease in ozone dissolved concentration found in the early stages of the catalytic decomposition. Moreover, aqueous ozone total removal was observed after $70 \mathrm{~min}$ in catalytic conditions while in the noncatalytic run total degradation was not observed even after $120 \mathrm{~min}$. Two mechanisms are proposed for the heterogeneous catalytic decomposition of ozone over metallic oxides: ozone adsorption with further decomposition into hydroxyl radicals [9] or ozone adsorption and decomposition into surface bounded active oxygen species as the highly active $\mathrm{O}^{-}$which will be responsible for oxidation reactions [29]. However, hydroxyl radicals are not generated in our catalytic system since, as proved earlier, the presence of radical scavengers does not affect the performance of catalytic ozonation over $\mathrm{Mn}-\mathrm{Ce}-\mathrm{O}$ (70/30). Therefore, it is likely that the catalytic degradation of the phenolic acids by ozone may mainly follow a mechanism of surface reactions involving the adsorption of both ozone and pollutants.

\section{Conclusions}

The efficiency of a Mn-Ce-O laboratorial catalyst to enhance catalytic ozonation of a phenolic wastewater under different operating conditions was assessed in this work. The use of the catalyst even in low quantities enhanced both $\mathrm{TPh}$ and TOC degradation. Single ozonation achieved $88 \%$ and $24 \%$ of reduction for TPh and TOC after 120 min of reaction, respectively, whereas, catalytic ozonation with the catalyst load optimized $(10 \mathrm{~g} / \mathrm{L})$ leads to total degradation of the phenolic content in $40 \mathrm{~min}$ and a final TOC reduction up to $74 \%$. The increase of $\mathrm{pH}$ enhanced single ozonation, while, contrarily, in catalytic ozonation, an inhibitory effect was observed in TOC degradation. This may be indicative of the absence of an aqueous hydroxyl radical pathway in catalytic ozonation over a Mn-Ce-O catalyst, which was confirmed by the fact that the presence of radical scavengers did not affect the process effectiveness. Therefore, within our results it is possible to conclude that catalytic ozonation over $\mathrm{Mn}-\mathrm{Ce}-\mathrm{O}$ develops mainly through surface reactions. The catalytic run had no effect over the catalyst morphology but a decrease on BET surface area was observed. The study of the effect of $\mathrm{pH}$ in Mn leaching pointed out that in all cases the Mn leached is a small ratio of the initial Mn loaded to the reactor and the lowest values are obtained for neutral medium pH. Moreover, the carbon content in the solution was removed by catalytic oxidation and not by adsorption on the solid catalyst since after 120 min of reaction a low quantity of carbon adsorbed at the catalyst was detected. Several feed-batch trials were performed in order to access the catalyst activity for long time operations. After the third run TOC removal stabilized in 50\% after 120 min of reaction whereas TPh was always totally removed. Ability of Mn-Ce-O to adsorb pollutants and decompose ozone was analyzed in order to understand the catalyst role in catalytic ozonation. These results show that catalytic ozonation enhanced by $\mathrm{Mn}-\mathrm{Ce}-\mathrm{O}$ seems to be a promising wastewater treatment.

\section{Acknowledgement}

Rui C. Martins gratefully acknowledges the Fundação para a Ciência e Tecnologia, Portugal, for the financial support under the PhD grant (BD/28854/2006).

\section{References}

[1] M. Carbajo, F. Beltrán, O. Gimeno, B. Acedo, F. Rivas, Appl. Catal. B 74 (2007) 203210.

[2] J. Beltran-Heredia, J. Torregrosa, J. Dominguez, J. Peres, Water Res. 35 (4) (2001) 1077-1085.

[3] A. Silva, E. Nouli, A. Carmo-Apolinário, N. Xekoukoulotakis, D. Mantzavinos, Catal. Today 124 (3-4) (2007) 232-239.

[4] F. Benitez, J. Beltrán-Heredia, J. Acero, M. Pinilla, Ind. Eng. Chem. Res. 36 (1997) 638-644.

[5] R. Andreozzi, A. Insola, V. Caprio, R. Marotta, V. Tufano, Appl. Catal. A 138 (1996) 75-81.

[6] R. Andreozzi, V. Capri, A. Insola, R. Marotta, V. Tufano, Water Res. 32 (5) (1998) 1492-1496.

[7] J. Villaseñor, P. Reyes, G. Pecchi, Catal. Today 76 (2002) 121-131.

[8] J. Ma, N. Graham, Water Res. 33 (3) (1998) 785-793.

[9] J. Ma, N. Graham, Water Res. 34 (15) (2000) 3822-3828.

[10] S. Tong, W. Liu, W. Leng, Q. Zhang, Chemosphere 50 (2003) 1359-1364.

[11] J. Ma, M. Sui, T. Zhang, C. Guan, Water Res. 39 (2005) 779-786.

[12] M. Sánchez-Polo, J. Rivera-Utrilla, U. von Gunten, Water Res. 40 (2006) 33753384.

[13] M. Alsheyab, A. Muñoz, Desalination 207 (2007) 179-183.

[14] F. Delanöe, B. Acedo, N. Karpel Vel Leitner, B. Legube, Appl. Catal. B 29 (2007) 315325.

[15] R. Lopes, A. Silva, R. Quinta-Ferreira, Appl. Catal. B 73 (2007) 193-202.

[16] A. Silva, I. Castelo-Branco, R. Quinta-Ferreira, J. Levec, Chem. Eng. Sci. 58 (2003) 177-186.

[17] A. Silva, R. Marques, R. Quinta-Ferreira, Appl. Catal. B 47 (2004) 269-279.

[18] A. Silva, A. Oliveira, R. Quinta-Ferreira, Chem. Eng. Sci. 59 (2004) 5291-5299.

[19] R. Martins, H.R. Leal, Quinta-Ferreira, in: S.I. Ao, M.A. Amouzegar, S. Chen (Eds.), Current Themes in Engineering Technologies, American Institute of Physics, New York, 2008, pp. 46-56.

[20] R. Martins, R. Quinta-Ferreira, Ind. Eng. Chem. Res. 48 (2009) 1196-1202.

[21] P. Faria, D. Monteiro, J. Órfão, M. Pereira, Chemosphere 74 (2009) 818-824.

[22] J. Rivera-Ultrilla, I. Bautista-Toledo, M. Ferro-García, C. Moreno-Castilla, J. Chem. Technol. Biotechnol. 76 (2001) 1209-1215.

[23] V. Balice, O. Cera, Grasas Aceites 35 (5) (1984) 178-180.

[24] A. Greenberg, L. Clesceri, A. Eaton, Standard Methods for the Examination of Water and Wastewater, American Public Health Association, Washington, DC, 1985. 
[25] F. Beltrán, J. García-Araya, I. Giráldez, Appl. Catal. B 63 (3-4) (2006) 249-259.

[26] S. Imamura, A. Dói, S. Ishida, Ind. Eng. Chem. Res. Dev. 24 (1985) 75-80.

[27] J. Staehelin, J. Hoigne, J. Environ. Sci. Technol. 16 (1982) 676-681.

[28] M. Pera-Titus, V. García-Molina, M. Baños, J. Giménez, S. Esplugas, Appl. Catal. B 47 (2004) 219-256

[29] M. Carbajo, F. Beltrán, F. Medina, O. Gimeno, F. Rivas, Appl. Catal. B 67 (2006) 177 186
[30] S. Hamoudi, F. Larachi, A. Sayari, J. Catal. 177 (1998) 247-258.

[31] B. Kasprzyk-Hordern, M. Ziólek, J. Nawrocki, Appl. Catal. B 46 (2003) 639669.

[32] P. Faria, J. Órfão, M. Pereira, Ind. Eng. Chem. Res. 45 (2006) 2715-2721.

[33] J. Lin, A. Kawai, T. Nakajima, Appl. Catal. B 39 (2002) 157-165.

[34] B. Dhandapani, S.T. Oyama, Appl. Catal. B 11 (1997) 129-166.

[35] A. Naydenov, R. Stoyanova, D. Mehandjev, J. Mol. Catal. A 98 (1995) 9-14. 